\title{
Niveles de linfocitos T y B en lactantes sanos
}

\author{
Dr. Edgardo Tomasello Hart. , y Sr. Julián Lozano Ríos **
}

Dado que la cuantificación de los linfocitos $T$ y $B$ en la sangre periférica constituye un método de indudable valor clínico, con grandes proyecciones a futuro $y$ no conociendo las cifras normales de estos parámetros en nuestro medio, decidimos estudiar estas dos subpoblaciones en lactantes sanos, eutróficos de nuestra población infantil.

Las aplicaciones clínicas actuales en las que se ha demostrado de interés estas determinaciones son el estudio de inmunodeficiencias, humorales, celulares o mixtas. Las inmunodeficiencias humorales pueden clasificarse en aquellas con número reducido o ausente de linfocitos B y con un número normal o aumentado. Se incluyen dentro de las primeras la mayor parte de las agamaglobulinemias ligados al cromosoma $\mathrm{X}$, algunos casos de agamaglobulinemia adquirida y de inmunodeficiencias mixtas graves. Entre los segundos la hipogamaglobulinemia ligada al cromosoma $X$ con hiper IgM, la hipogamablobulinemia transitoria de la infancia, y la deficiencia selectiva de IgA.

\footnotetext{
*Servicio de Pediatría Hospital Van Buren, Docente U. de Chile; Departamento de Pediatría Valparaiso.

**Boquimico Departamento Medicina Experimental U. de Chile, Valparaíso.
}

En la mayor parte de las inmunodeficiencias celulares, incluyendo las inmunodeficiencias mixtas (Síndrome de Di George, Síndrome de Nezelof, Ataxia Telagiectasia, Síndrome de Wiscot-Aldrich), los linfocitos $T$ están notoriamente disminuidos, generalmente en relación a la gravedad de la deficiencia de la inmunidad celular.

El estudio de los linfocitos $\mathrm{T}$ y $\mathrm{B}$ ha permitido la clasificación de los síndromes linfoproliferativos y Leucocis en neoplasias de tipo $T$ o B. La proliferación linfocítica que está presente en la Leucemia crónica linfática casi siempre representa una proliferación de células $\mathrm{B}$, al igual que la mayor parte de los Linfosarcomas y linfomas tipo Burkitt. En el caso de la leucemia linfática aguda, la determinación de células $T$ ha sugerido que esta puede ser inducida por virus y tienden a ser producidas en niños más pequeños. En otros casos no se han detectado células tipo $\mathrm{T}$ ni $\mathrm{B}$, catalogándoselas como células tipo "null".

En desnutriciones calórica-proteicas graves, el porcentaje y número absoluto de linfocitos $T$ está notoriamente reducido existiendo una correlación de la susceptibilidad de estos ninos a las infecciones. Al mejorar el estado 
nutricional se produce una normalización de estos porcentajes.

En niños de bajo peso con malnutrición intrauterina se ha determinado un fenómeno səmejante.

En enfermedades de tipo autoinmune se ha demostrado un aumento de linfocitos $T$ en sangre periférica como es el caso Hipertiroidismo y Tiroidit is de Hashimoto.

Finalmente, en enfermedades de causa desconocida, la determinación de linfocitos $\mathbf{T} y$ $B$ puede indicar los roles relativos de la inmunidad celular y humoral en su patogenia.

\section{MATERIAL Y METODO}

Se midieron los niveles de Linfocitos $\mathrm{T}$ y $\mathrm{B}$ en 18 lactantes sanos provenientes del Consultorio Hospital de Niños del Hospital "Carlos Van Buren" de Valparaíso. Las muestras se obtuvieron por punción venosa, las edades fluctuaron entre 8 días y 18 meses de edad.

Se escogieron niños clínicamente sanos y sin antecedentes de patología en los últimos 10 días. Todos eran eutróficos y sin carencias nutricionales.

\section{PURIFICACIÓN DE LINFOCTTOS}

Se extrajeron 2-3 $\mathrm{ml}$ de sangre por punción venosa usando como anticoagulante CPD (Ac. Cítrico-Fosfato-Dextrosa). La muestra fue defibrinada dentro de las dos horas de obtenida agregando $0,05 \mathrm{ml}$ de CaCl1 $21 \mathrm{M}$ y agitando por $10 \mathrm{~min}$. con perlas de vidrio. Después de separar el coágulo, el suero con los elementos celulares se incubó por $15 \mathrm{~min}$. a $37^{\circ} \mathrm{C}$ con $50 \mathrm{mg}$ de Hierro metálico (Merck.) con objeto de eliminar las células fagocíticas. Estas fueron luego separadas con ayuda de un imán. La muestra fue luego diluída con un volúmen igual de amortiguador TRIS - $\mathrm{NaCl} 0,14 \mathrm{M}$ ph 7,4.

Los linfocitos se separaron colocando esta mezcla sobre una solución de Ficoll-Hipaque de densidad $1,077 \mathrm{~g} / \mathrm{lt}$ y centrifugando luego a $400 \mathrm{~g}$ por $25 \mathrm{~min}$. a temperatura ambiente. Las células de la interfase fueron separadas y lavadas tres veces con solución balanceada de Hanks (HBSS) y luego ajustadas a una concentración de 10.000 células por $\mathrm{mm}^{3}$. Se obtuvieron entre $\mathbf{9 0 - 9 2 \%}$ de linfocitos con una viabi- lidad cercana al $100 \%$ medida por el método de exclusión con Azul Tripan.

Las determinaciones de linfocitos $T$ y $B$ fueron efectuados en forma simultánea en todas las muestras.

\section{Ensayo de la Roseta E.}

Se efectuó usando como marcador de membrana glóbulos rojos de cordero (GRC) mantenidos en solución de Alsever. Los GRC se lavaron tres veces en suero fisiológico y se ajustaron luego a una concentración de $0,5 \%$ en HBSS.

Para obtener las Rosetas E se mezclaron 50 microlitros de la suspensión purificada de linfocitos con 50 microlitros de suero normal humano tipo AB, el cual previamente se inactivó por 30 minutos a $56^{\circ} \mathrm{C}$ y se absorbió con GRC al $50 \%$ en HBSS por 30 minutos a $37^{\circ} \mathrm{C}$ y luego por 30 minutos a $4^{\circ} \mathrm{C}$ antes de usar. A la mezcla anterior se agregaron 100 microlitros de la suspensión de GRC a, 0,5\% en HBSS, luego de centrifugar a $100 \mathrm{~g}$ por 5 minutos se dejaron 16 horas a $4^{\circ} \mathrm{C}$.

Las células fueron luego resuspendidas suavemente por agitamiento y se agregó una gota de Azul de Metileno al 1\%, se contaron por lo menos 200 células en cámara de Malassez, considerando como rosetas aquellas células que tenían adheridos por lo menos 3 GRC.

Todas las determinaciones fueron hechas por duplicado expresándose los resultados en porcentajes de Linfocitos $\mathrm{T}$ y en número absoluto como Linfocitos $T$ por $\mathrm{mm}^{3}$ de sangre.

\section{Ensayo de la Roseta EaC}

Se sensibilizaron GRC al $0,5 \%$ con un volúmen igual de Hemolisina anti-GRC (BBL Laboratorys, Beckton Dickinson, USA) diluída 1/9600 en Suero fisiológico y con suero de ratón diluido $1 / 10$ como fuente de complemento, esta solución se incubó por 30 minutos a $37^{\circ} \mathrm{C}$. Posteriormente se lavaron los GRC sensibilizados por tres veces con suero fisiológico. Para el ensayo de la Roseta EAC se incubaron $0,1 \mathrm{ml}$ de la suspensión de linfocitos purificados, con $0,1 \mathrm{ml}$ de suspensión de GRC sensibilizados al $0,5 \%$ a $37^{\circ} \mathrm{C}$ por $30 \mathrm{~min}$. previa centrifugación a $100 \mathrm{~g}$ por $5 \mathrm{~min}$. Se resuspendieron suavemente por agitación y se agregó 1 gota de Azul de Meti - 
leno al $1 \%$ y se contaron las rosetas y los linfocitos libres de manera similar al ensayo de la Roseta E.

\section{RESULTADOS}

Los resultados de la determinación de niveles sanguíneos de linfocitos $T$ y $B$ y del número absoluto de linfocitos totales se muestran en la Tabla I.
Para linfocitos $T$ se encontró un valor en porcentaje de $46,8 \%$ (D.E.: $\pm 18,8$ ) correspondiendo una concentración de 1980 por $\mathrm{mm}^{3}$ (D.E.: \pm 855 ). La medida correspondiente a linfocitos B fue de $29,5 \%$ (D.E.: $\pm 7,3$ ) con una concentración de 1242 por $\mathrm{mm}^{3}$ (D.E.: \pm 553 ).

El número absoluto de linfocitos fue de 4299 por $\mathrm{mm}^{3}$ (D.E \pm 1441 y su porcentaje de 46,9 (D.E.: \pm 15 ).

Tabla 1

LINFOCITOS T Y B EN LACTANTES SANOS

\begin{tabular}{|c|c|c|c|c|}
\hline & \multicolumn{2}{|c|}{ Porcentaje } & \multicolumn{2}{|c|}{ Número absoluto (por $\mathrm{mm}^{3}$ ) } \\
\hline & Media \pm 1 de & Rango & Media \pm de & Rango \\
\hline Linfocitos $T$ & $46,8 \pm 18,8$ & $20,9-67,8$ & $1980 \pm 855$ & $473-4004$ \\
\hline Linfocitos B & $29,6 \pm 7,3$ & $17-41,5$ & $1242 \pm 553$ & $453-2774$ \\
\hline Linfocitos & $46,9 \pm 15$ & -76 & $4299 \pm 1411$ & $2190-7600$ \\
\hline
\end{tabular}

La variación del porcentaje y número absoluto de linfocitos $T$ con la edad muestra un ascenso progresivo en los primeros meses, estabilizándose aproximadamente a los 12 meses de edad, este fenómeno se aprecia claramente al expresar los valores de linfocitos $\mathrm{T}$ en porcentaje, sin embargo al expresarlo en número absoluto por $\mathrm{mm}^{\mathrm{s}}$ se observa un ascenso que no se estabilizáa los 18 meses (Fig. 1).

Por otro lado, los linfocitos B muestran una leve tendencia descendente al relacionarlos con la edad, tanto en porcentaje como en número absoluto por $\mathrm{mm}^{3}$ (Fig. 2).

\section{DISCUSION}

La cuantificación de subpoblaciones linfocitarias $\mathrm{T}$ y $\mathrm{B}$ han sido efectuadas extensivamente en adultos, en lactantes solo conocemos los trabajos de Fleisher y Matsaniotis usando lactantes sanos, los resultados obtenidos en este trabajo concuerdan con los obtenidos por estos autores.

Fundamentalmente hemos encontrado que los linfocitos $T$ medidos a través de la técnica de la Roseta $\mathrm{E}$ y expresados en porcentajes de linfocitos totales se encuentran muy bajos durante los primeros dos meses de vida del lac- tante al compararlo con los valores obtenidos para sujetos normales adultos, sin embargo comparados respecto a los valores absolutos, por $\mathrm{mm}^{3}$, los valores de lactantes son superiores a los adultos, hecho que se puede explicar por la linfocitosis fisiológica que presentan estos niños.

El ascenso posterior que experimentan estos valores se explicaría por la estimulación antigénica a la cual se ven sometidos los lactantes en este periodo de desarrollo (gran frecuencia de infecciones virales especialmente) lo cual diferenciaria células linfocitarias, posiblemente aquellas con características de "null cells" hacia linfocitos $\mathrm{T}$ activos.

Por otra parte, los linfocitos B se encuentran en cifras más elevadas que el adulto, expresadas tanto en porcentaje como respecto al número absoluto de linfocitos, lo cual podría reflejar una concentración relativa frente a las exigencias de inmunoglobulinas que se produce en este período de desarrollo. A medida que transcurren los meses se observa un leve descenso en estos valores, tanto en porcentaje como en número absoluto, posiblemente reflejando un efecto de dilución al aumentar paralelamente el número de los linfocitos $\mathrm{T}$. 

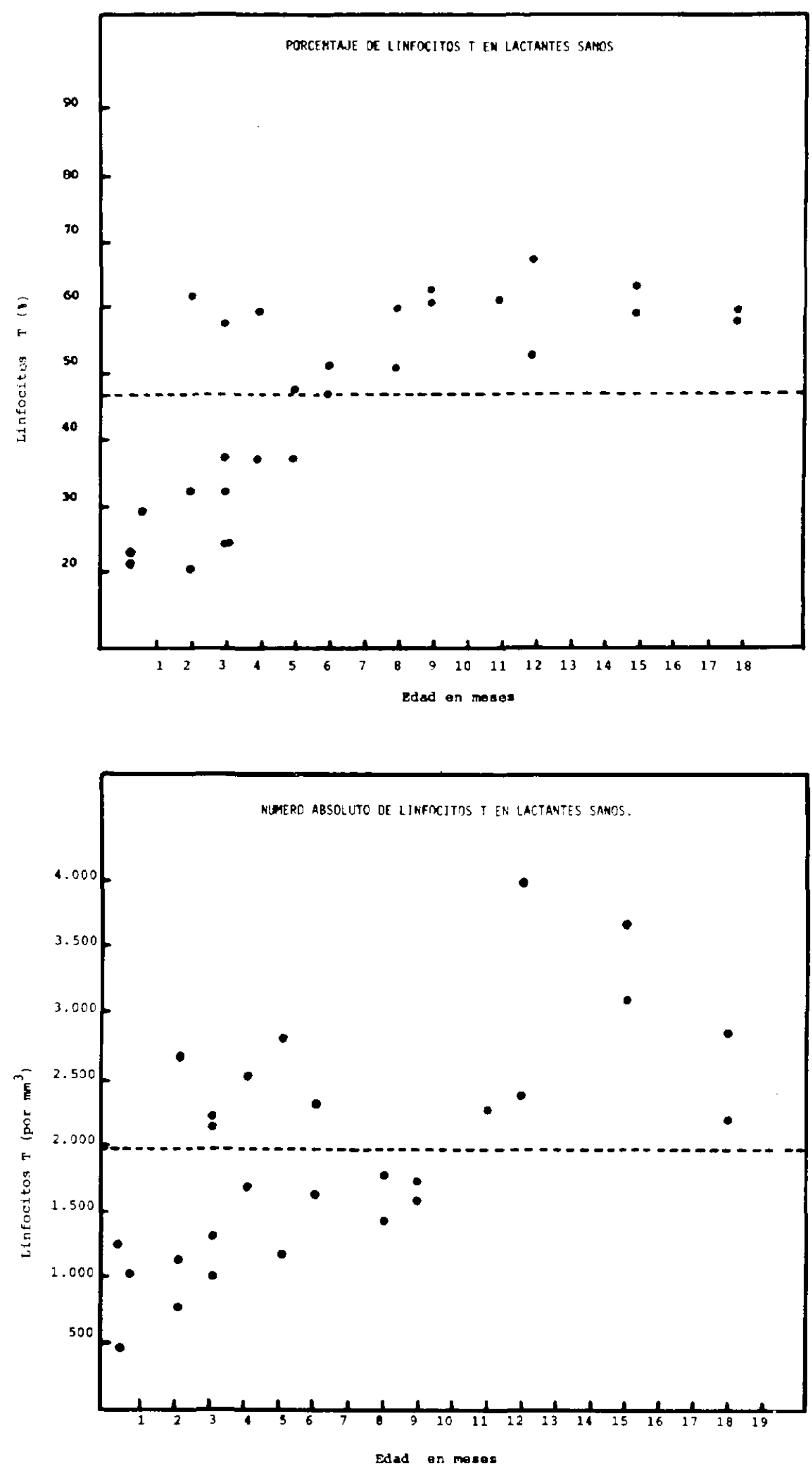

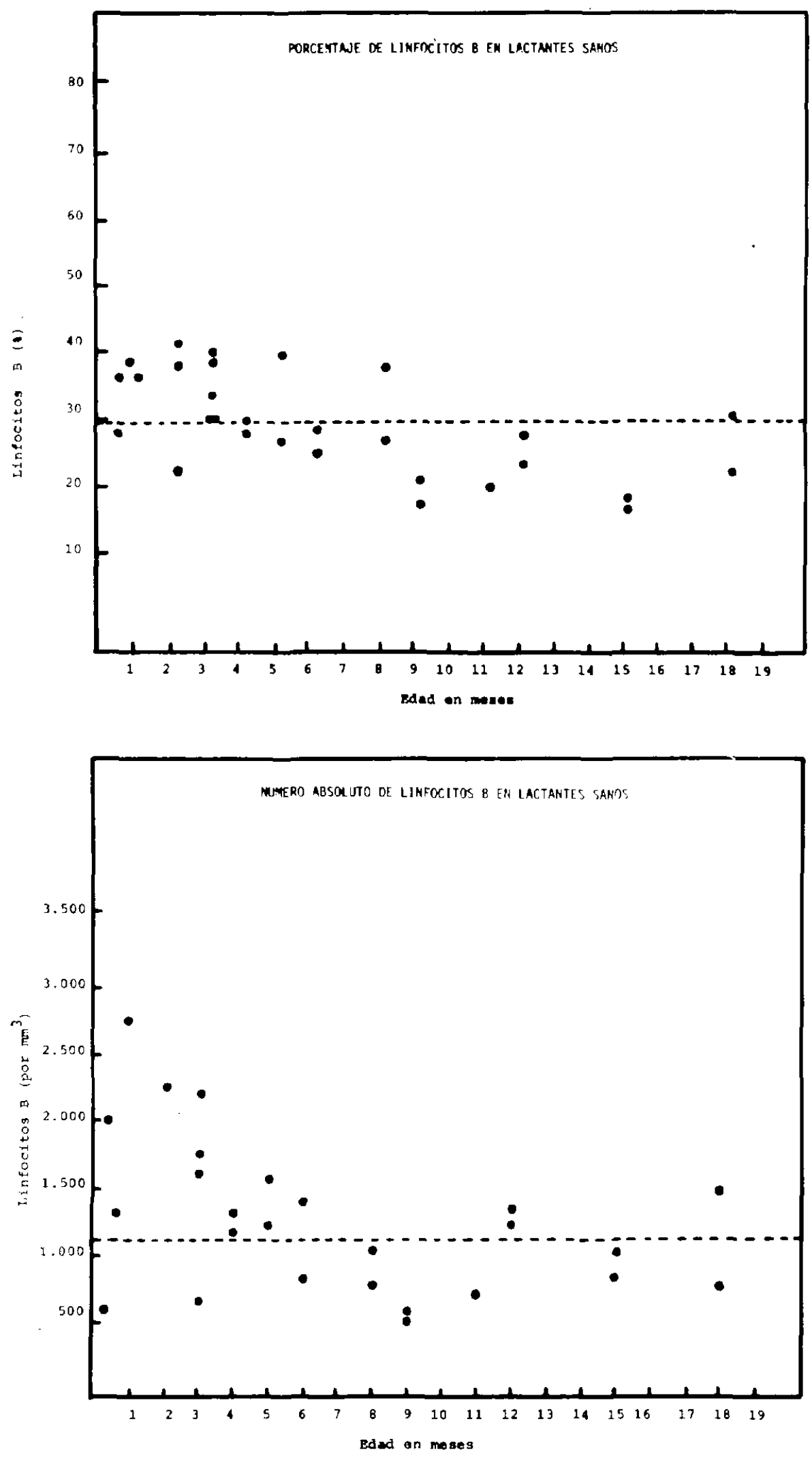


\section{REFERENCIAS}

' Fletsher, T.A.; Luckasen, J.R.; Sabad, A. et al.: T and $B$ lymphocyte subpopulations. Pediatrics, 55:162, 1975.

2 Matsaniotis, N.; Mantanelaki-Asifi, C.; Apostoton, M. et al. Age dependance of $\mathrm{T}$ cells. Br. Med. J. 3:743, 1974

3 Raff, M.D. T y B lymphocytes and inmune responses. Nature. 242:19, 1973.

- Aiuti, F., Cerottini, J.C.; Coombs, R.R.A., et al. Identification, enumeration, and isolation of $B$ and $T$ lymphocytes from human peripheral blood. Scand. J. Inmunol. 3:521, 1974.

5 Jondal, M., Wigzell, H., and Aıti, F. Human lymphocyte subpopulations: Classification according to surface markers and/or functional characteristics. Transplant. Rev. 16:163, 1973

6 Broun, G., and Greaves, M.F. Cell surface markers for human $\mathrm{T}$ and B lymphocytes. Eur. J. Immunol 4:302, 1974.

7 Brown, G., and Greaves, M.F. Enumeration of absolute numbers of $\mathbf{T}$ and $B$ lymphocytes in human blood. Scand. J. Immunol. 3:161, 1974

8 Wybran, J., Carr, M.C., and Fundenberg, H.H. The human rosette forming cell as a marker of a population of thymes derived cells. J. Clin. Invest. 51:2537, 1972.

y Wybran, J., and Fudenberg, H.H. How clinically useful is $\mathrm{T}$ and $\mathrm{B}$ cell quantitation? Ann. Intern. Med. $80: 765,1974$.
10 Cooper, M.D., and Lazton, A.R. Circulating B cells in patients with immunodeficiency. Am. J. Pathol. $69: 513,1972$

1 Wybran, J., Levin, A.S., Spitler, L.E., et al. Roseteforming cells, immunologic deficiency diseases, and transfer factor. N. Engl. J. Med. 288:7 10, 1973.

1.2 Seligmann., M., Preudhomme, J.L., and Brouet, J.C. $\mathrm{B}$ and $\mathrm{T}$ ceil markers in human proliferation blood diseases and primary immunodeficiencies, with special reference to membrane bound immunoglobulins Trasplant. Rev. 16:85, 1973.

is Kersey, J.H., Gaijl-Peezalska, K.J., and Nesbit, M.E. The lymphoid system: Abnormalities in immunodeficiency and malignancy. J. Pediatr. 84:789, 1974.

14 Wybran, J., and Fudenberg, H.H. Thymus-derived rosette-forming cells in various human disease states: Cancer, lymphoma, bacterial and viral infections and other diseases. J. Clin. Invest. 52: 1025, 1973.

15 Ferguson, A.C., Lawlor, G.J., Jr., Neumann, C.C., and Stiehm, E.R. Decreased rosette-forming lymphocytes in malnutrition nnd intrauterine growth retardation. J. Pediatr. 85:717, 1974.

16 Farid, N.R., Munro, R.E., Row, V.V., and Volpé, $\boldsymbol{R}$. Peripheral thymus-dependent (T) lumphocytes in Graves diseaseand Hashimoto's thyroiditis. N. Engl. J. Med. 288:1313, 1973

17 Talal, N., Sylvester, R.A., Daniels, T.E. Greenspan, V.S., and Williams, R.C., Jr. T and B Lymphocytes in peripheral blood and tissue lesions in Sjögren's syndrome. J. Clin. Invest., 53:180, 1974. 